\title{
Aluminum oxyhydroxide-doped PMMA hybrids powder prepared via facile one-pot method towards copper ion removal from aqueous solution
}

\author{
Misagh Ghamari ${ }^{1} \cdot$ Amin Imani $^{2} \cdot$ James F. Williams ${ }^{3} \cdot$ Mahdi Ghasemifard $^{1,3}$
}

Received: 2 June 2019 / Accepted: 28 October 2019 / Published online: 7 November 2019

(c) The Author(s) 2019

\section{Abstract}

A novel polymethyl methacrylate/boehmite nanocomposite with remarkably enhanced adsorption performance of $\mathrm{Cu}$ (II) was synthesized from $\mathrm{Al}\left(\mathrm{NO}_{3}\right)_{3} \cdot 9 \mathrm{H}_{2} \mathrm{O}$ using a facile sol-gel method. The effects of boehmite content, contact time and morphology of hybrid (pH of synthesis) as the main parameters on removal efficiency and removal capability of hybrid on copper ions have been explored. Composites contained between 0.7 and $5 \mathrm{wt} \%$ boehmite content and those with dissimilar morphology prepared with different $\mathrm{pH}$ values showed different adsorption behavior. Batch adsorption experiments show that the adsorption performance of the hybrids was enhanced with increased boehmite and contact time. The highest removal efficiency and adsorption capability were achieved when the hybrid was prepared at pH 8 with associated increased catalytic activity.

\section{Graphic abstract}

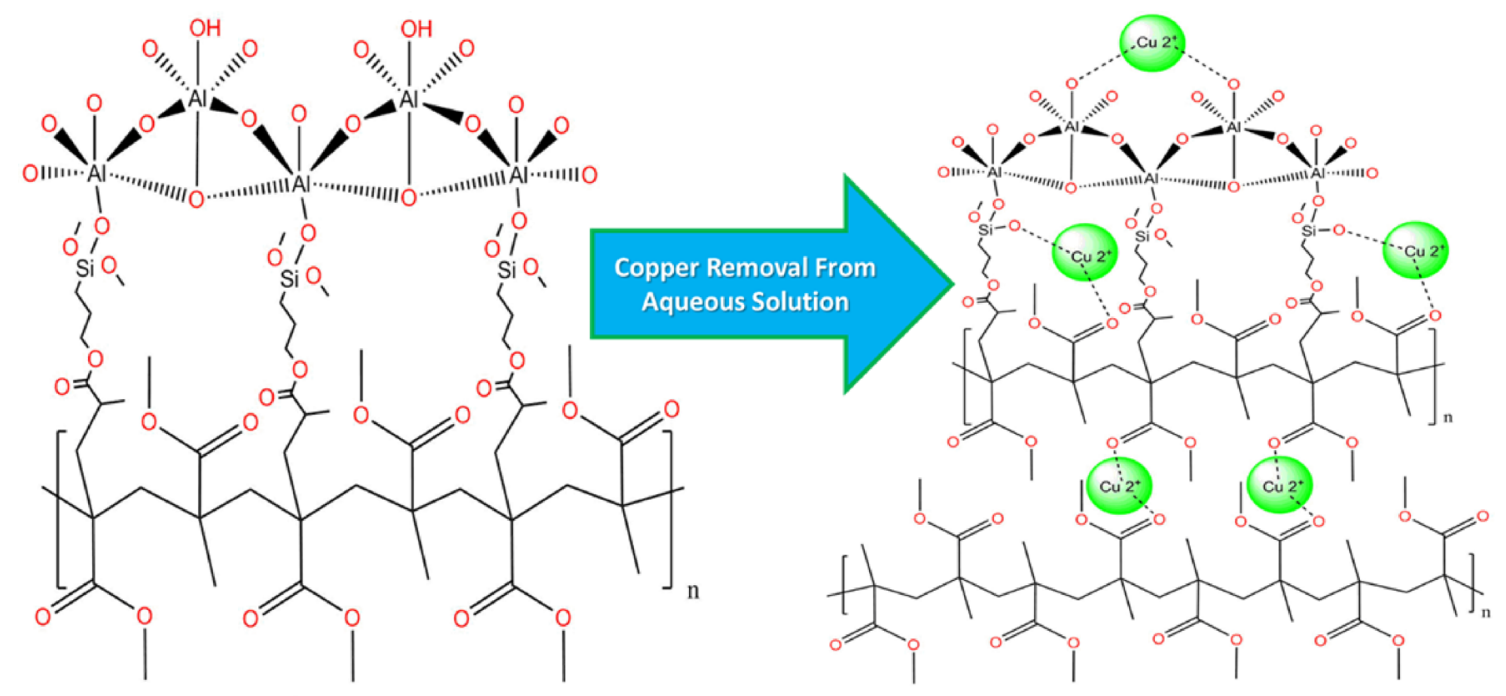

PMMA/BO Nanohybrids

The removal of Copper (II) by PMMA doped with boehmite hybrids

Mahdi Ghasemifard

mahdi.ghasemifard@gmail.com

Extended author information available on the last page of the article 


\section{Highlights}

- PMMA/aluminum oxyhydroxide hybrids act as a good $\mathrm{Cu}$ adsorbent

- The absorption behavior depends on hybrid morphology

- The higher surface area of hybrids provides a great capability to absorb $\mathrm{Cu}$ ions in aqueous media

Keywords PMMA $\cdot$ Boehmite $\cdot$ Copper ion $\cdot$ Hybrid $\cdot$ Morphology

\section{Introduction}

The pollution of water via toxic heavy metals through the evacuation of industrial wastewater is a global environmental issue [1]. Growing industrialization has resulted in the discharge of toxic heavy metals, such as copper, lead, arsenic, cadmium, and chromium [2-4] into water. Since heavy metals generally tend to accumulate in living organisms over time, their toxicity may result in many hazardous circumstances such as damage to blood composition, lungs, kidneys, liver, and other vital organs. Copper has been identified as a contaminant due to its prevalent existence and toxic effect upon the environment. It catalyzes the development of highly reactive oxygen species, which leads to lipid peroxidation and the lack of the compact form of glutathione which rises the methemoglobin content [5]. Additional $\mathrm{Cu}^{+2}$ in the human body has been related to severe health problems such as cellular or main organ disease [6]. To reduce or avoid major toxic effects on ecosystems, it is desirable to develop and improve highly selective and efficient tools to remove/recover metal ions from natural and waste water which has become an imperative problem [7].

Studies have been made to create the economic and efficient adsorbents for heavy metal ion removal [8-10]. The Al-based nanostructures containing aluminum oxide, aluminum hydroxide, and aluminum oxyhydroxide have been broadly investigated due to their outstanding physicochemical features for $\mathrm{Cu}$ (II) removal $[11,12]$. The different chemical features of AlOOH surface facilitate many applications in advanced catalysts [13] and heavy metal adsorbents [14]. Boehmite has many acidic sites on its surface which facilitate copper complexes adsorption in different aqueous media. However, these materials have some problems of agglomeration, complex separation procedure, and costly recovery methods. Polymethyl methacrylate (PMMA) has been commonly utilized as an adaptable polymer due to its exclusive benefits, such as excellent optical transparency, good solvent resistance, low cost, low density, chemical resistance, and good physicomechanical properties [15-17]. These properties enable PMMA to use in many practical applications, for example, optical and supercapacitor, medicine, automobile industries, and hydrogen storage materials $[18,19]$. However, PMMA has some disadvantages of a brittle texture, low thermal and mechanical stability and inadequate surface hardness, for example, the addition of metal oxide materials to the polymer matrix results in increased activity of the polymer and its thermal and mechanical functions.

Recently, the organic/inorganic hybrid materials with proper chemical diversity and mechanical stability for adsorption uses have attracted a great deal of attention. There are some methods to synthesize polymer-based nanocomposites such as physical mixing, in situ polymerization, and sol-gel-based routes and changes in the mixing ratios of components. In physical mixing, the two components are synthesized first and then mixed physically to increase relative homogeneity; however, disadvantages of an inappropriate scale of mixing and lack of strong bonding may occur. In situ polymerization uses the surface-modified nanoparticles which interact with an organic phase during polymerization and whose size determines the mixing ratios. The creation of PMMA and boehmite nanohybrids via the one-pot process (sol-gel-based) results in the formation of numerous chemically dynamic sites which are adsorbent in their fine structures. It is noteworthy that the sol-gel process is capable of forming the fine structures by starting the reactions directly from relevant precursors which facilitate the homogeneous mixing of organic and inorganic ingredients [20]. Adsorption is considered a smart method that permits flexibility in scheme and operation, regeneration of the adsorbent by appropriate desorption process, and it is highly effective and more economic.

In this work, we synthesize the PMMA/boehmite hybrids through sol-gel single-source approach using methyl methacrylate and aluminum nitrate as precursors to reach high homogeneity with many active sites for $\mathrm{Cu}$ (II) capture from aqueous media. The time of interaction and the effect of hybrid morphology on the adsorption efficiency are discussed.

\section{Materials and methods}

Aluminum nitrate nonahydrate, methyl methacrylate, ammonium persulfate (APS), sodium dodecyl sulfate (SDS), 3-methacryloxy propyl trimethoxy silane, copper(II) nitrate, and ammonia solution (37\%) all from Merck were used without further purification. 


\section{Synthesis of PMMA/boehmite nanocomposite}

The PMMA/AlOOH nanohybrids were prepared via a facile sol-gel single-source method starting directly from relevant precursors at different $\mathrm{pH}$ according to the procedure described in previous work [20]. First, $2.82 \mathrm{~g}$ methyl methacrylate (MMA) added to $0.065 \mathrm{~g} 3$-methacryloxy propyl trimethoxy silane and mixed with the solution of $0.3 \mathrm{~g}$ surfactant SDS in $60 \mathrm{ml}$ deionized water to form micelles. The $\mathrm{pH}$ was adjusted using ammonia solution to the anticipated value. The solution was then shifted to the 3 -necked roundbottom glass reactor which is prepared with a thermometer and $\mathrm{N}_{2}$ inlet to remove $\mathrm{O}_{2}$. Then, reaching the temperature to $80{ }^{\circ} \mathrm{C}, 4 \mathrm{ml}$ APS $0.15 \mathrm{M}$ was added to the reactor to start the polymerization. Finally, $20 \mathrm{ml}$ aluminum nitrate solution $0.025 \mathrm{M}$ was added, dropwise, to the reactor with strong stirring as BO precursor. PMMA/boehmite nano-hybrids with boehmite contents of $0.74,2.60$, and $5.00 \%$, known briefly as HNM7, HNM26, and HNM50, respectively, were prepared.

\section{Adsorption experiments}

The prepared colloidal particles were washed three times with hot deionized water and ethanol to remove the soluble ingredients and then dried in an oven at $60{ }^{\circ} \mathrm{C}$ for $24 \mathrm{~h}$ to lose the physical water. The copper solution of $1000 \mathrm{mg} / \mathrm{l}$ was prepared by dissolving copper nitrate in deionized water and the required concentration obtained by diluting at ambient conditions. The experiment was conducted in a conical flask through the addition of the hybrid powder into copper-containing water. The obtained mixture was stirred at $300 \mathrm{rpm}$ with the contact time varied from 15 to $90 \mathrm{~min}$. The hybrid was removed by centrifugation and filtered through a filter membrane. The removal efficiency and adsorption capacity are based on the different concentrations of solutions as follows:

Removal efficiency $(\%)=\frac{C_{0}-C_{\mathrm{e}}}{C_{0}} \times 100$,

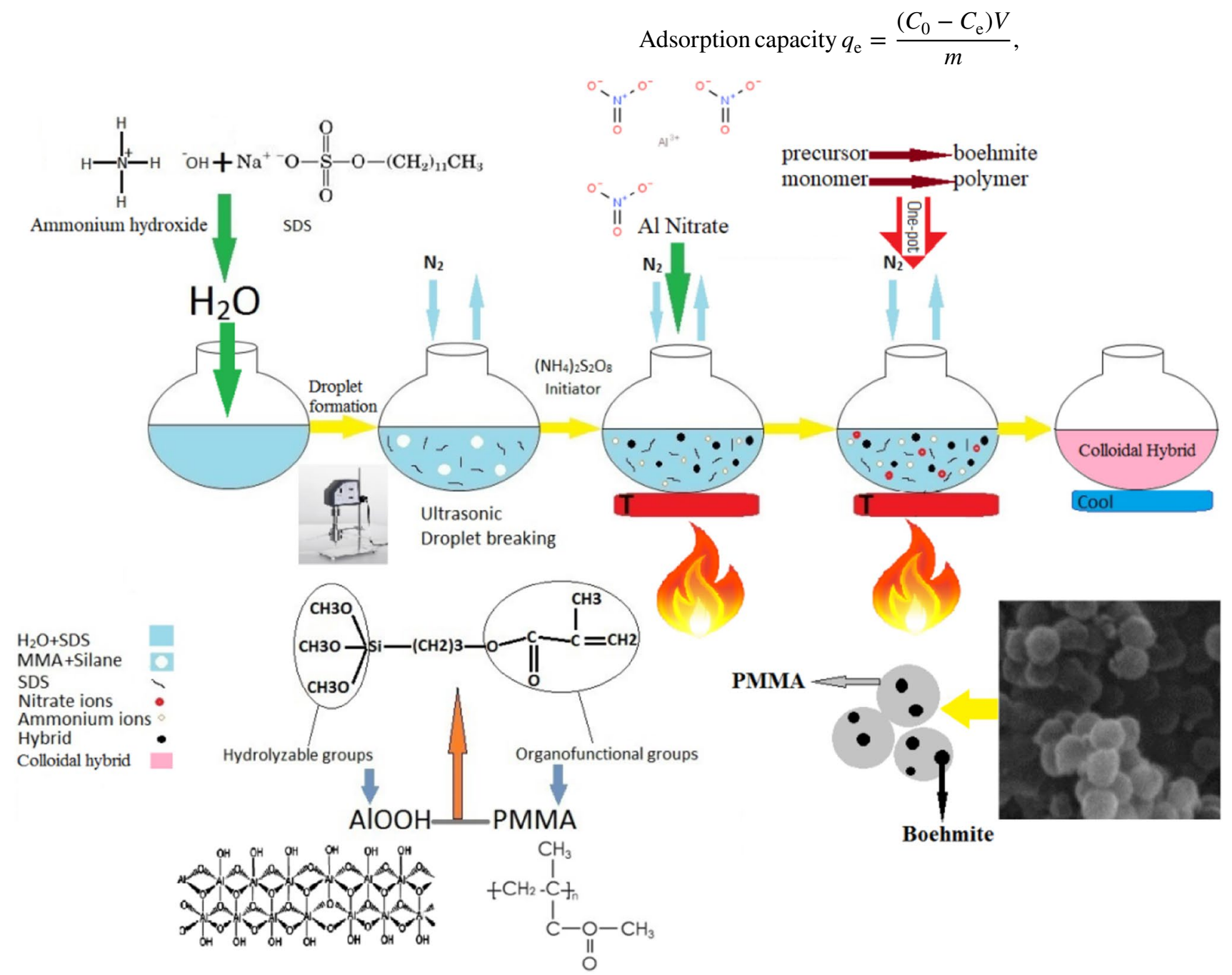

Scheme 1 A representation of the overall procedure from precursor to ion removal experiment 
where $C_{0}$ and $C_{\mathrm{e}}$ are the initial and final (steady-state) concentrations of $\mathrm{Cu}(\mathrm{II})$, respectively; $m(\mathrm{~g})$ is the hybrid mass, and $V(\mathrm{~L})$ is the volume of solution.

\section{Results and discussion}

\section{Preparation of hybrid}

The overall procedures to produce PMMA/boehmite hybrid nanoparticles via the sol-gel method are illustrated schematically in Scheme 1. Good dispersion of boehmite nanoparticles in the polymer matrix, while preventing particle agglomeration can also help to introduce new levels of interfacial phase. Because the absorption of copper ions occurs in certain sites of the hybrid, such as hydroxyl groups, it can be seen that the proper dispersion of boehmite particles in the polymer is of great importance and performing chemical reactions from the precursors can increase the possibility of achieving homogeneous structures.

\section{The effect of $\mathrm{pH}$ on the microstructure of hybrids}

The FTIR spectra of samples including pristine PMMA and hybrids are demonstrated in Fig. 1. Since the adsorption peak at $1636 \mathrm{~cm}^{-1}$ cannot be seen, the $\mathrm{C}=\mathrm{C}$ double bond has been changed to the single bond in both monomer and silane. The asymmetric and symmetric stretching vibrations of the methylene and methyl species in $2850-3050 \mathrm{~cm}^{-1}$ are identified [21] and show intensities growing with samples containing more silane (more BO). On the other hand, the increasing trend in adsorption at $2958 \mathrm{~cm}^{-1}$ [22] can be

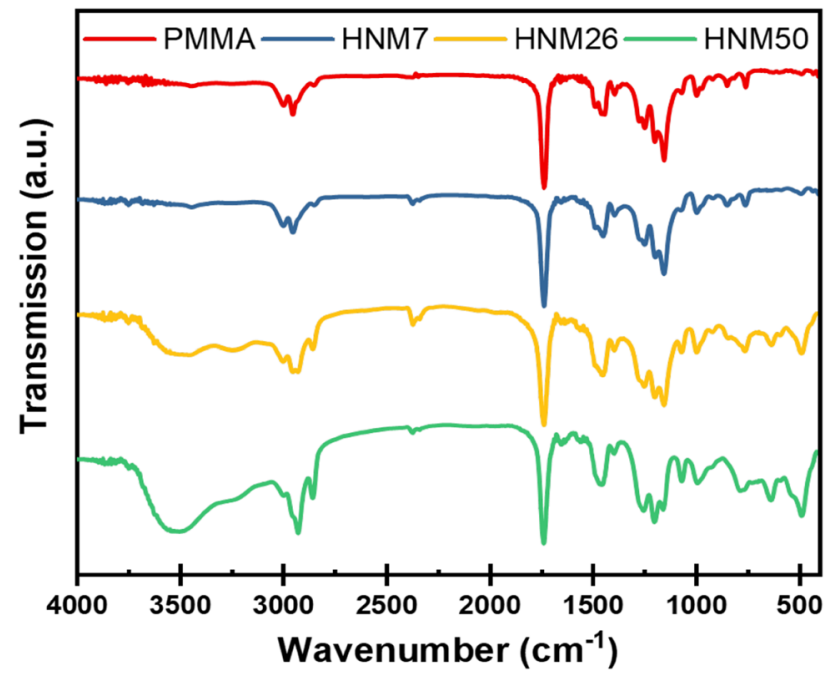

Fig. 1 FTIR spectra of pristine PMMA and hybrids clarified with more involvement of silane coupling agents with raising the $\mathrm{BO}$ content.

Carbonyl groups $\mathrm{C}=\mathrm{O}$ are kept constant during reactions since they do not participate in the chemical fluctuations and as verified from the peak at $1731 \mathrm{~cm}^{-1}$ in all samples [23]. The fixed position of the carbonyl group results from the absence of ionic bonding between boehmite hydroxyl groups and polymer functional groups [24]. With increasing BO content, the peaks at frequencies up to $1000 \mathrm{~cm}^{-1}\left(481 \mathrm{~cm}^{-1}\right.$ and $583 \mathrm{~cm}^{-1}$ ) increase which is due to more metal-oxygen interactions. The clearly increasing trend in the intensity of peaks at $3300-3800 \mathrm{~cm}^{-1}$ with increasing $\mathrm{BO}$ indicates the hydroxyl groups of $\mathrm{BO}$ in the hybrid. The $\mathrm{Si}-\mathrm{O}-\mathrm{Al}$ bonds $\left(627 \mathrm{~cm}^{-1}\right)$ cannot be seen for PMMA alone but are detected for hybrids containing silane [25].

The TGA results of hybrids and PMMA are shown in Fig. 2 for experiments carried out at ambient conditions with three weight changes. The first weight loss mainly up to $150{ }^{\circ} \mathrm{C}$ (negligible) may be associated with water and oligomers remaining in the samples [20].

The other step is related to polymer backbone decomposition in the range of $300-400{ }^{\circ} \mathrm{C}$, while the last step is due to transition alumina formation [26] from $\mathrm{AlOOH}$ starting at $450{ }^{\circ} \mathrm{C}$ due to the $2 \mathrm{AlOOH}=\mathrm{Al}_{2} \mathrm{O}_{3}+\mathrm{H}_{2} \mathrm{O}$ reaction.

As indicated in Fig. 2, the samples with more $\mathrm{BO}$ seem to be more thermally stable. The incorporation of more $\mathrm{BO}$ into PMMA structure may protect the polymer from side effects of heating. The maximum degradation temperature of the hybrids shifts to higher temperatures as the amount of $\mathrm{BO}$ is increased. The improvement of the thermal stability by including $\mathrm{AlOOH}$ seems to be due to the variations of polymer chain mobility [27] and a radical trapping effect of

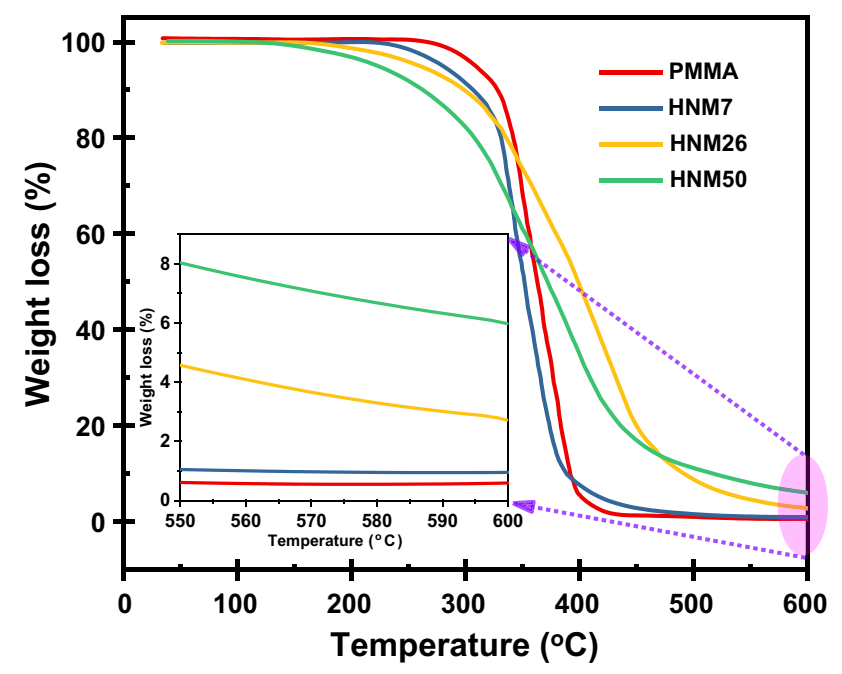

Fig. 2 TGA thermograms of the pure PMMA and different hybrids 

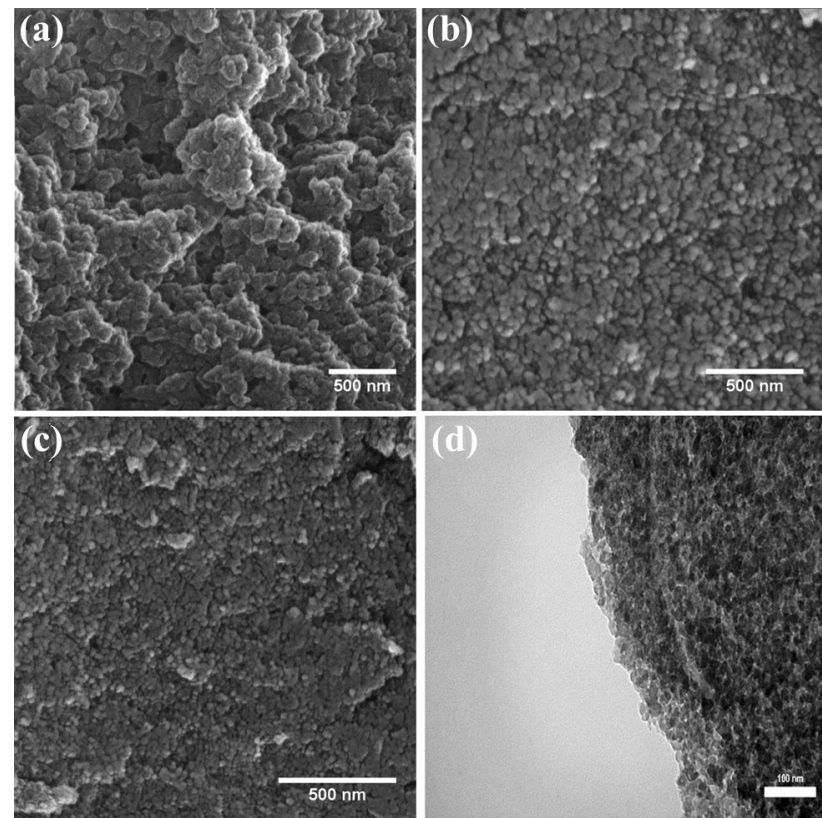

Fig. 3 FE-SEM images of hybrids prepared at different $\mathrm{pH}$. a pH 7, b $\mathrm{pH} 8, \mathbf{c} \mathrm{pH} 9$ and $\mathbf{d}$ TEM image of hybrid prepared at $\mathrm{pH} 8$

BO and adsorption of polymer chains on filler surfaces via the methoxycarbonyl groups.

Much research shows the correlation between the morphology of hybrid and some physical and chemical properties. The impact of the $\mathrm{pH}$ of the synthesis on the morphology of hybrid nanoparticles has been assessed by means of field emission SEM (FE-SEM) (Fig. 3). As seen clearly, cauliflower and semispherical particles are formed under acidic and alkaline situations with a combined morphology of both shown in the sample prepared at $\mathrm{pH}$ 8. Normally, in acidic conditions, the number of $\mathrm{H}_{3} \mathrm{O}^{+}$moieties increases consequently resulting in the dissolution of $\mathrm{Al}$ based species which in turn increases the rate of nucleation with lowering of particles size and the mesh-like structure of PMMA and $\mathrm{AlOOH}$ can be attained. Figure $3 \mathrm{~d}$ shows the TEM images of prepared hybrid synthesized at $\mathrm{pH} 8$. The study of organic-inorganic hybrids is significantly improved by TEM. The contrast observed in images is attributed mainly to density differences between the organic and inorganic phases. In the hybrid materials studied, the organic and inorganic phases are sufficiently different in density (about $100 \%$ ) to create good inherent contrast in the TEM.

In alkaline conditions, for comparison, decreasing $\mathrm{H}_{3} \mathrm{O}^{+}$ while increasing the $\mathrm{OH}^{-}$concentration lowers the nucleation at the expense of increasing the growth of particle size. Thus, fewer particles with larger size are formed than occurs for acidic situations. The presence of negative ions in liquid may cause relative stability of particles by repulsive forces which in turn make hybrids as segregated particles with fairly saturated $\mathrm{Al}^{3+}$ by hydroxyl groups [20].

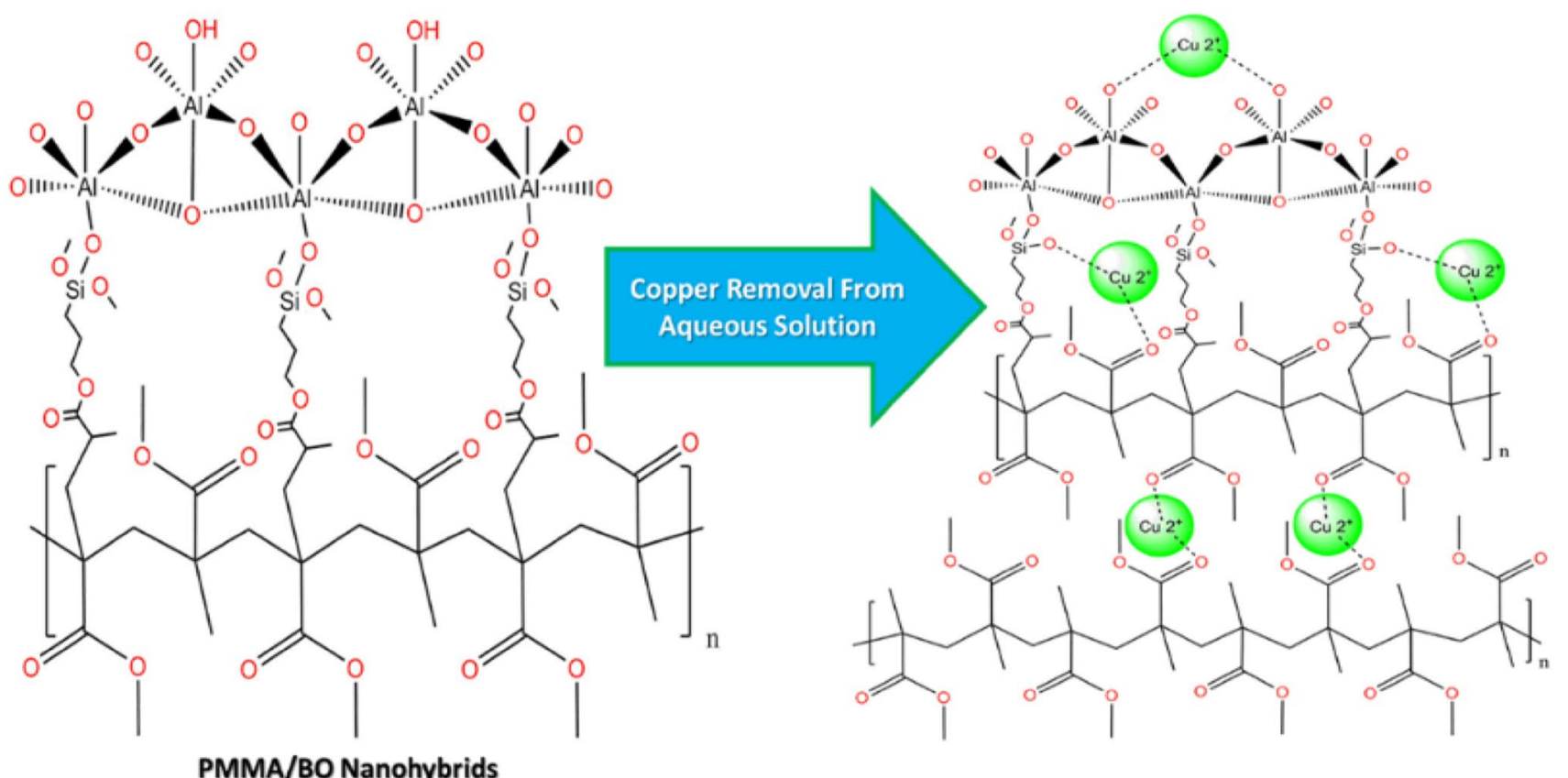

Scheme 2 Schematic illustration of the removal of copper(II) by PMMA doped with boehmite hybrids 

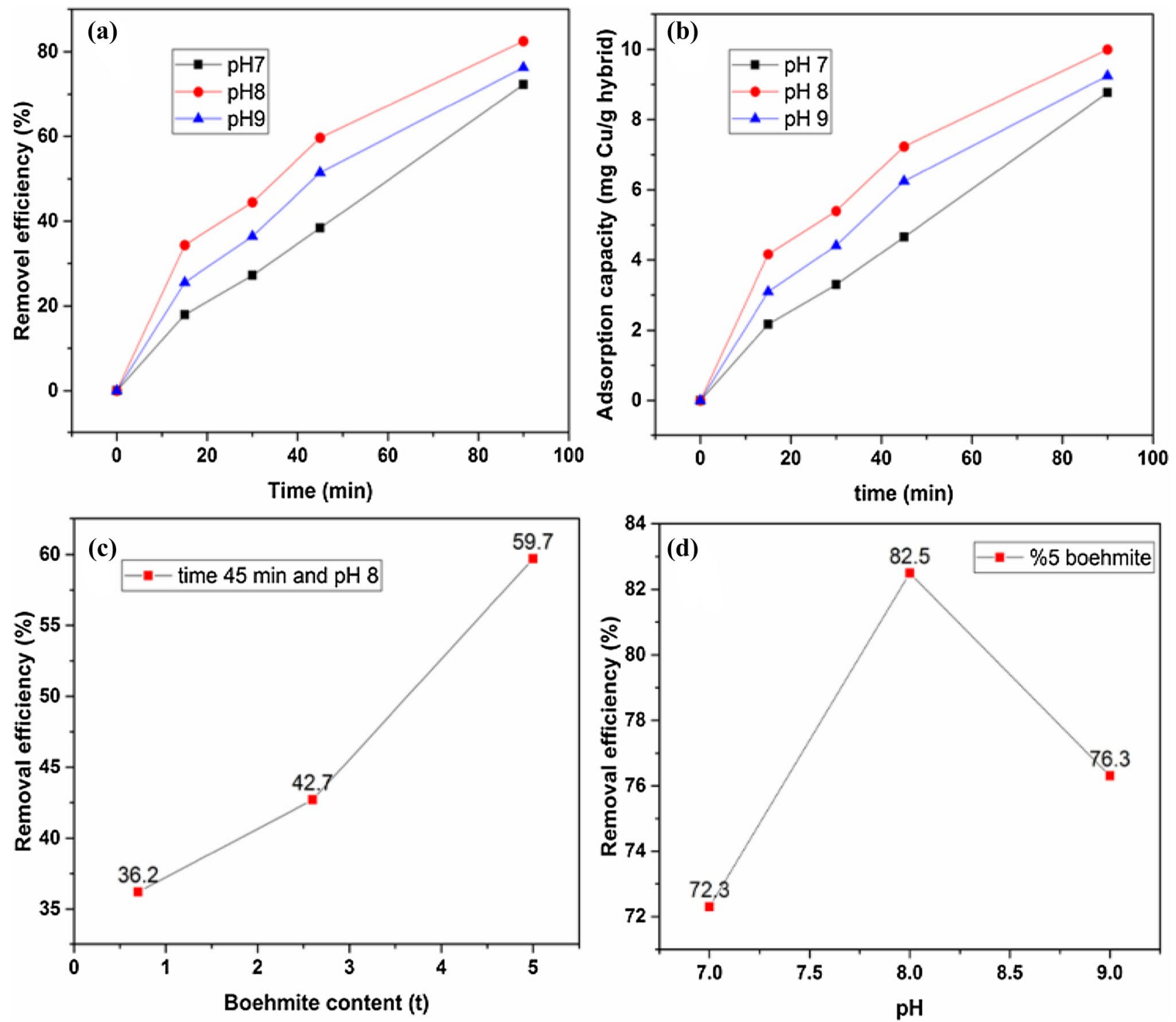

Fig. 4 a The removal efficiency of hybrids prepared at different $\mathrm{pH}$. b The adsorption capacity of hybrid particles for copper ions removal at different $\mathrm{pH}$. $\mathbf{c}$ Removal efficiency of a hybrid at $\mathrm{pH} 8$ and $45 \mathrm{~min}$ contact time. d Effect of $\mathrm{pH}$ of synthesis on removal efficiency of hybrids

\section{Effect of contact time on removal efficiency and adsorption capacity}

The removal of Copper ion by means of PMMA/BO hybrids was studied and the effect of two important parameters including the prepared $\mathrm{pH}$ and contact time was monitored. Scheme 2 is an illustration of copper ion adsorbed on the hybrid. The removal efficiency of hybrid particles is plotted in Fig. 4a. It is apparent that the $\mathrm{pH}$ in which samples are prepared plays an important role to the adsorption capacity of adsorbents due to its impact on the internal structure of the hybrid which in turn affects the removal efficiency of copper ions in aqueous media. Since PMMA has relatively negligible porosity, the maximum removal efficiency is achieved in $\mathrm{pH} 8$ since the maximum pore volume and surface area of boehmite occurred for this $\mathrm{pH}$.

According to Fig. 4a, removal efficiency reaches higher values in $\mathrm{pH}$ 8. The adsorption capacity of copper ions by hybrid is plotted vs. time of contact for hybrid prepared at different $\mathrm{pH}$ in Fig. 4b. Then, the adsorption capacity in all $\mathrm{pH}$ values increases as contact time increases. The adsorption capacity reached $10 \mathrm{mg}$ of copper per gram of hybrid in samples prepared at $\mathrm{pH} 8$ and contact time of $90 \mathrm{~min}$.

The results reveal that the adsorption process at relatively fast kinetics as a result of the high level of reachable active sites occurred on the different parts of hybrid which 


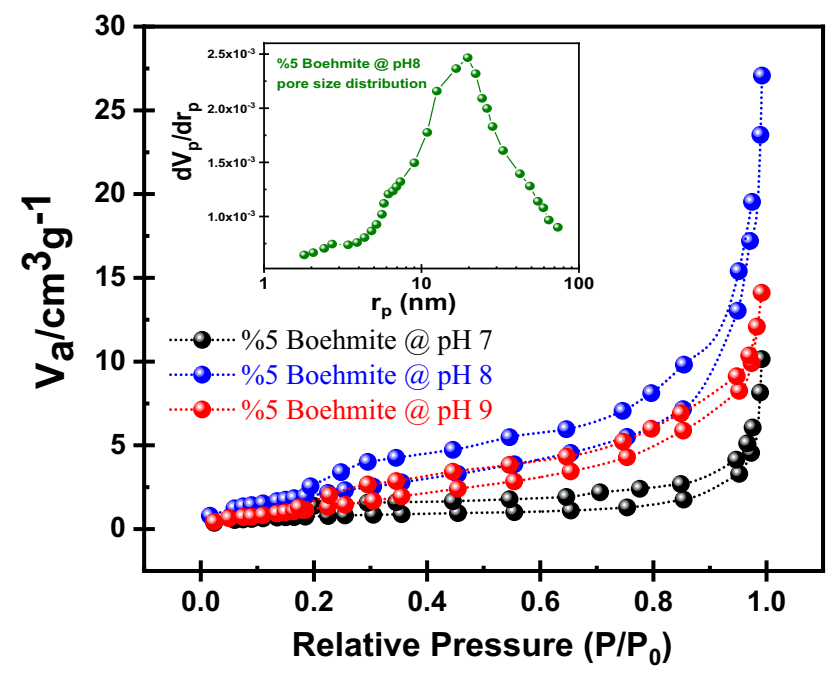

Fig. 5 Nitrogen adsorption-desorption isotherms of nanoporous hybrids. The inset shows BJH pore size distribution of $5 \%$ boehmite@pH8, derived from the adsorption branch of the nitrogen adsorption/desorption isotherm

facilitate the proper interaction between copper ions with these sites.

\section{Effect of boehmite content on removal efficiency}

It is well known that boehmite as oxyhydroxide of aluminum can be used in water applications [28, 29]. However, the use of nanoscale particles can be more effective than traditional ones because of their increased activity in the microstructure. The high surface area of boehmite is seen to have a large capacity to absorb copper ions in aqueous media.

The removal efficiency of samples at $\mathrm{pH} 8$ for samples with different boehmite contents for 45 min exposure has been shown in Fig. 4c. The hydroxyl groups of boehmite particles are a good candidate for adsorbing copper ions in aqueous solutions. The removal efficiency increases with increasing boehmite and the number of hydroxyl groups increases; consequently, the tendency of these groups is to increase the absorption of copper ions in the medium.

As can be seen, the removal efficiency of hybrid increases as boehmite increases. The values of removal efficiency at different $\mathrm{pH}$ for the hybrid containing $5 \mathrm{wt} \%$ boehmite are illustrated in Fig. 4d.

The internal structure of boehmite differs extensively by adjusting the $\mathrm{pH}$ of synthesis. On the other side, the $\mathrm{pH}$ can modify the microstructure of the hybrid, as well. The overall interaction of different parameters resulted in reaching removal efficiency to the maximum value in $\mathrm{pH}$. The $\mathrm{pH}$ values 7 and 9 did not introduce sufficient porous structure to the hybrid so that removal efficiency and adsorption capacity are smaller than with $\mathrm{pH} 8$. On the other hand, in $\mathrm{pH} 9$, the bayerite phase with less surface and porosity compared with boehmite is enhanced.

The specific surface area of the hybrids was determined by nitrogen adsorption-desorption measurements to increase understanding of the sample porosities. The nitrogen adsorption-desorption isotherms (Fig. 5) attained via the reflux method show the capillary condensation step. The isotherms of the samples can be considered as type IV with a hysteresis loop which specifies the nanoporous nature of the hybrids [30]. The considered Brunauer-Emmett-Teller (BET) surface area from the adsorption branch revealed that hybrids prepared at $\mathrm{pH} 8$ had the highest value of $21.17 \mathrm{~m}^{2} / \mathrm{g}$ in contrast with other hybrids. Also Fig. 5 (inset) shows that the pore size distribution of the prepared hybrid at $\mathrm{pH} 8$ has the majority of the pores contained in the main region, (with nanopores structure about $15-25 \mathrm{~nm}$ ), whereas other hybrids displayed a larger pore size about $50 \mathrm{~nm}$. Higher surface area and lower pore size lead to a growth in absorption capacity and removal efficiency.

The results established that varying synthesis $\mathrm{pH}$ changed the specific surface area and pore size distribution, which was confirmed by the morphology presented in the SEM images (Fig. 3).

\section{Conclusions}

The capability of PMMA/boehmite hybrid nanoparticles for copper ion removal from aqueous mediums was shown. The effects of $\mathrm{pH}$ of synthesis, boehmite content in hybrid, and contact time on removal efficiency were explored. The results showed the increasing trend in the removal capability of hybrids towards copper with increasing contact time and boehmite content. The maximum removal efficiency was achieved for hybrids prepared at $\mathrm{pH}$ 8. The removal efficiency increased from 36 to $60 \mathrm{mg} / \mathrm{g}$ by boehmite more incorporation from $0.7 \%$ to $5 \mathrm{wt} \%$ in $\mathrm{pH} 8$ and time $45 \mathrm{~min}$.

Open Access This article is distributed under the terms of the Creative Commons Attribution 4.0 International License (http://creativeco mmons.org/licenses/by/4.0/), which permits unrestricted use, distribution, and reproduction in any medium, provided you give appropriate credit to the original author(s) and the source, provide a link to the Creative Commons license, and indicate if changes were made.

\section{References}

1. Wang, Q., Yang, Z.: Industrial water pollution, water environment treatment, and health risks in China. Environ. Pollut. 218, 358-365 (2016). https://doi.org/10.1016/j.envpol.2016.07.011

2. Asgari Lajayer, B., Najafi, N., Moghiseh, E., Mosaferi, M., Hadian, J.: Removal of heavy metals $\left(\mathrm{Cu}^{2+}\right.$ and $\left.\mathrm{Cd}^{2+}\right)$ from effluent using gamma irradiation, titanium dioxide nanoparticles and 
methanol. J. Nanostructure Chem. 8, 483-496 (2018). https://doi. org/10.1007/s40097-018-0292-3

3. Asgari Lajayer, B., Ghorbanpour, M., Nikabadi, S.: Heavy metals in contaminated environment: destiny of secondary metabolite biosynthesis, oxidative status and phytoextraction in medicinal plants. Ecotoxicol. Environ. Saf. 145, 377-390 (2017). https:// doi.org/10.1016/j.ecoenv.2017.07.035

4. Sadegh, H., Ali, G.A.M., Gupta, V.K., Makhlouf, A.S.H., Shahryari-ghoshekandi, R., Nadagouda, M.N., Sillanpää, M., Megiel, E.: The role of nanomaterials as effective adsorbents and their applications in wastewater treatment. J. Nanostructure Chem. 7, 1-14 (2017). https://doi.org/10.1007/s40097-017-0219-4

5. Ali Sarhan, A.: Adsorption characteristics of copper(II) ions from aqueous solution onto ionic cross-linked Pva/P(Aam-Nipaam) core-shell nanogels. J. Nanomed. Nanotechnol. 01, 1-9 (2015). https://doi.org/10.4172/2157-7439.S7-001

6. Tisato, F., Marzano, C., Porchia, M., Pellei, M., Santini, C.: Copper in diseases and treatments, and copper-based anticancer strategies. Med. Res. Rev. (2009). https://doi.org/10.1002/med.20174

7. Muhammad Ekramul Mahmud, H.N., Huq, A.K.O., Yahya, R. binti: The removal of heavy metal ions from wastewater/aqueous solution using polypyrrole-based adsorbents: a review. RSC Adv. 6, 14778-14791 (2016). https://doi.org/10.1039/c5ra24358k

8. Ali, R.M., Hamad, H.A., Hussein, M.M., Malash, G.F.: Potential of using green adsorbent of heavy metal removal from aqueous solutions: adsorption kinetics, isotherm, thermodynamic, mechanism and economic analysis. Ecol. Eng. 91, 317-332 (2016). https ://doi.org/10.1016/j.ecoleng.2016.03.015

9. Khoshsang, H., Ghaffarinejad, A., Kazemi, H., Wang, Y., Arandiyan, H.: One-pot synthesis of S-doped $\mathrm{Fe}_{2} \mathrm{O}_{3} / \mathrm{C}$ magnetic nanocomposite as an adsorbent for anionic dye removal: equilibrium and kinetic studies. J. Nanostructure Chem. 8, 23-32 (2018). https ://doi.org/10.1007/s40097-017-0251-4

10. Khandel, P., Shahi, S.K.: Mycogenic nanoparticles and their bioprospective applications: current status and future challenges. J. Nanostructure Chem. 8, 369-391 (2018). https://doi.org/10.1007/ s40097-018-0285-2

11. Ghaemi, N., Daraei, P.: Enhancement in copper ion removal by PPy@ $\mathrm{Al}_{2} \mathrm{O}_{3}$ polymeric nanocomposite membrane. J. Ind. Eng. Chem. 40, 26-33 (2016). https://doi.org/10.1016/j. jiec.2016.05.027

12. Fouladgar, M., Beheshti, M., Sabzyan, H.: Single and binary adsorption of nickel and copper from aqueous solutions by $\gamma$-alumina nanoparticles: equilibrium and kinetic modeling. J. Mol. Liq. 211, 1060-1073 (2015). https://doi.org/10.1016/j.molli q.2015.08.029

13. Xu, Z., Yu, J., Jaroniec, M.: Efficient catalytic removal of formaldehyde at room temperature using $\mathrm{AlOOH}$ nanoflakes with deposited Pt. Appl. Catal. B Environ. 163, 306-312 (2015). https ://doi.org/10.1016/j.apcatb.2014.08.017

14. Sun, B., Li, X., Zhao, R., Yin, M., Wang, Z., Jiang, Z., Wang, C.: Hierarchical aminated PAN $/ \gamma$-AlOOH electrospun composite nanofibers and their heavy metal ion adsorption performance. J. Taiwan Inst. Chem. Eng. 62, 219-227 (2016). https://doi. org/10.1016/j.jtice.2016.02.008

15. Dinari, M., Mohammadnezhad, G., Soltani, R.: Fabrication of poly(methyl methacrylate)/silica KIT-6 nanocomposites via in situ polymerization approach and their application for removal of $\mathrm{Cu}^{2+}$ from aqueous solution. RSC Adv. 6, 11419-11429 (2016). https ://doi.org/10.1039/C5RA23500F

16. Ghamari, M., Farzi, G.: Effect of morphology control on optical properties of PMMA/boehmite nano-hybrid prepared through facile one-pot process. J. Mater. Sci. Mater. Electron. 28, 16570 16574 (2017). https://doi.org/10.1007/s10854-017-7570-6

17. Mohammadnezhad, G., Dinari, M., Soltani, R.: The preparation of modified boehmite/PMMA nanocomposites by: in situ polymerization and the assessment of their capability for $\mathrm{Cu}^{2+}$ ion removal. New J. Chem. 40, 3612-3621 (2016). https://doi. org/10.1039/c5nj03109e

18. Sun, W., Li, L., Stefanescu, E.A., Kessler, M.R., Bowler, N.: Dynamics of poly(methyl methacrylate)-montmorillonite nanocomposites: a dielectric study. J. Non Cryst. Solids. 410, 43-50 (2015). https://doi.org/10.1016/j.jnoncrysol.2014.11.030

19. Trung, N.B., Tam, T.Van, Dang, D.K., Babu, K.F., Kim, E.J., Kim, J., Choi, W.M.: Facile synthesis of three-dimensional graphene/nickel oxide nanoparticles composites for high performance supercapacitor electrodes. Chem. Eng. J. 264, 603-609 (2015). https://doi.org/10.1016/j.cej.2014.11.140

20. Ghamari, M., Farzi, G.: The impact of morphology control on the microhardness of PMMA/boehmite hybrid nanoparticles prepared via facile aqueous one-pot process. J. Sol Gel Sci. Technol. 84 135-144 (2017). https://doi.org/10.1007/s10971-017-4487-8

21. Ghamari, M., Farzi, G.: Frequency and composition dependency of optical and dielectric properties of PMMA/boehmite nanohybrid prepared via facile aqueous one-pot process. Mod. Phys. Lett. B 31, 1750120 (2017). https://doi.org/10.1142/S021798491 7501202

22. Park, S.Y., Park, E.J., Lee, M.Y., Park, C., Kim, H.G., Jeong, E.D., Lim, K.T.: Preparation of $\mathrm{Al}(\mathrm{OH})_{3} / \mathrm{PMMA}$ nanocomposites by emulsion polymerization. Polym. Adv. Technol. 19, 1803-1808 (2008). https://doi.org/10.1002/pat.1197

23. Imani, A., Arabi, M., Farzi, G.: Effect of in situ oxidative preparation on electrical properties of epoxy/PANi/MWCNTs nanocomposites. J. Mater. Sci.: Mater. Electron. 27, 10364-10370 (2016). https://doi.org/10.1007/s10854-016-5122-0

24. Grohens, Y., Schultz, J., Prud'homme, R.E.: PMMA conformational changes on $\gamma$-alumina powder: influence of the polymer tacticity on the configuration of the adsorbed layer. Int. J. Adhes. Adhes. 17, 163-167 (1997). https://doi.org/10.1016/s0143 -7496(96)00035-8

25. Pantoja, M., Díaz-Benito, B., Velasco, F., Abenojar, J., del Real, J.C.: Analysis of hydrolysis process of $\gamma$-methacryloxypropyltrim ethoxysilane and its influence on the formation of silane coatings on 6063 aluminum alloy. Appl. Surf. Sci. 255, 6386-6390 (2009). https://doi.org/10.1016/j.apsusc.2009.02.022

26. Naskar, M.K., Chatterjee, M.: Boehmite nanoparticles by the tworeverse emulsion technique. J. Am. Ceram. Soc. 88, 3322-3326 (2005). https://doi.org/10.1111/j.1551-2916.2005.00600.x

27. Laachachi, A., Ferriol, M., Cochez, M., Lopez Cuesta, J.-M., Ruch, D.: A comparison of the role of boehmite $(\mathrm{AlOOH})$ and alumina $\left(\mathrm{Al}_{2} \mathrm{O}_{3}\right)$ in the thermal stability and flammability of poly(methyl methacrylate). Polym. Degrad. Stab. 94, 1373-1378 (2009). https://doi.org/10.1016/j.polymdegradstab.2009.05.014

28. Miao, Y.E., Wang, R., Chen, D., Liu, Z., Liu, T.: Electrospun selfstanding membrane of hierarchical $\mathrm{SiO}_{2}$ at $\gamma$ - $\mathrm{AlOOH}$ (Boehmite) core/sheath fibers for water remediation. ACS Appl. Mater. Interfaces 4, 5353-5359 (2012). https://doi.org/10.1021/am3012998

29. Rajamani, M., Rajendrakumar, K.: Chitosan-boehmite desiccant composite as a promising adsorbent towards heavy metal removal. J. Environ. Manag. 244, 257-264 (2019). https://doi. org/10.1016/j.jenvman.2019.05.056

30. Imani, A., Oveisi, H.: Self-assembly assisted fabrication of nanoporous nickel(II) phosphate octahydrate microspheres catalyst with orange peel surface toward urea oxidation. ChemistrySelect 4, 7338-7342 (2019). https://doi.org/10.1002/slct.201901107

Publisher's Note Springer Nature remains neutral with regard to jurisdictional claims in published maps and institutional affiliations. 


\section{Affiliations}

\section{Misagh Ghamari ${ }^{1} \cdot$ Amin Imani $^{2} \cdot$ James F. Williams ${ }^{3} \cdot$ Mahdi Ghasemifard $^{1,3}$}

1 Nanotechnology Lab, Esfarayen University of Technology, Esfarayen, Iran

2 Department of Materials Engineering, The University of British Columbia, Vancouver, BC V6T 1Z4, Canada
3 Department of Physics, The University of Western Australia, 35 Stirling Highway, Perth, WA 6009, Australia 